\title{
EDITORIAL: The Rise of Interdisciplinarity
}

Throughout its long history, the academia has always entangled with the debates about disciplinarity, now with the most recent debates about interdisciplinarity. These debates reflect, in some form or other of the paradox: disciplines vs. interdisciplines.

In the past, until the end of nineteenth century, disciplinarity was clearly shaped outside interests such as economic, cultural, and political. For example, the rise of industrialization and technology, the growth of the natural and social sciences, and the rise of a bourgeois class helped to determine the structure and boundary of the disciplines. Academic disciplines were articulated, what Michel Foucault termed the "dividing practices," as demanded by the academia. They vary in the ways they structure themselves, maintain boundaries, regulate practitioners, and communicate with each other. Thus, in the universities, faculties along with departments came to function in relative isolation from each other.

With the rise of interdisciplinarity in the twentieth century, there is an attempt to focus on freedom of knowledge and inquiry against external pressures of society and entrenched modes of disciplinarity. After the World War I, interdisciplinarity in its first historical expression was explicitly counter-disciplinary and was interested in the reform. The focus at this time was on integrative knowledge, involving two or more academic disciplines at a time. These challenges, called as 'critical interdisciplinarity', continue today in the form of area studies, women's studies, postcolonial studies, race studies, queer studies, and cultural studies, among others. These modes of knowledge cut across traditional institutional boundaries at the same time as they question traditional ways of knowing and learning.

Under the rubric of interdisciplinarity, we must commit ourselves to new formations of knowledge and inquiry and, at the same time, to the constitution of new learning communities. Interdisciplinarity should give expression to a modality of scholarly activity that works self-consciously and responsibly to ask the question about the very existence of disciplinary boundaries of knowledge.

Crossing the Border: International Journal of Interdisciplinary Studies is the outcome of these debates around interdisciplinarity and against disciplinarity. The journal is categorically divided into four broad topics, which cover the diverse areas of study, crossing the borders of each subject undertaken. They are as follow:

Part I: Gender, Power and Visual Culture

Part II: Technology, Globalization and the Third World

Part III: Literature and Society

Part IV: Race, Ethnicity and the Politics of Identity

Each topic includes research articles, dealing with academic disciplines into one activity that capture the sentiment of interdisciplinarity. Each topic relates to broad subjects that have been discussed and interpreted from different perspective.

Part I: Gender, Power and Visual Culture is about visual culture that deals with the topics related to gender and power. Visual culture can be seen as an interdisciplinary field of study which focuses on a broadly defined problem of visuality. The study of visual culture defined by its interdisciplinary study of images across media, architecture, design and art across a range of social arenas, namely, news, art, science, 
advertising and popular culture. Indira Mishra and Jiblal Sapkota, through their articles, present an overview of different ways in which visual culture can be approached from diversified feminist perspectives. They comment on the existing modes of feminist reading of visual culture and, more importantly, to explore and develop effective theoretical and analytical tools which would facilitate a thorough and innovative analysis of the visual.

Part II: Technology, Globalization and the Third World discusses current trends in the globalization of technology and economies to developing countries, and the current disparities that exist. Nilam K. Sharma, in his article, discusses the reasons for many developing nations that have limited access to international market, and steps to be taken for them to better their economic status. His article focuses on the areas of labour, capital inflow, trade, technology transfer and socio-cultural issues. Min Pun explores the impact of different forms of the globalization of technology on developing countries, in which two disciplines such as technology and teaching intersect. However, this does not automatically imply that developing countries succeed to benefit from technological advances. He traces the role of technology in English language teaching, summarizing some of the key global trends which are making it more difficult for developing countries.

Part III: Literature and Society deals with looking at literature as sociological commentary. All good literature approaches the world around the author and characters with a skeptical eye, often moving social and political events that surround the plot developments to the foreground as a literary device. The authors, Rajendra P. Tiwari, Dharma Thapa and Badri Prasad Pokharel analyze the works of fiction from the intedisciplinary perspective in order to examine the use of society as a literary device and often as a character in the story at hand. They together claim that the kinds of issues discussed by each mode of understanding the world perform similar functions in helping us to understand the world that give us different ways of understanding society and our place in it.

Part IV: Race, Ethnicity and the Politics of Identity discusses how race and ethnicity are woven into the fabric of Nepali politics and society. It deals with the ways race and ethnicity matter in society and the consequences of this for people's lives. To this end, the articles of this section address the following questions: What are the social and historical processes that have shaped our understandings of race and ethnicity? How have racial inequalities developed over time? In our exploration of these questions, the articles are the key readings in racial and indigenous studies that lay out central concepts, theories, and historical contexts. Prakash Upadhyay and Ram Chandra Paudel examine ethnic identity politics by first reviewing the respective roles of ethnic identity and politics in group conflict. In discussing ethnic identity politics, they try to explain its prevalence, with special attention to its possible psychological and social functions. They then review the ways in which the political process is rooted in conflict, as well as the special place that group identity has in politics. Next, Lal S. Rapacha, thinking across disciplines, describes ethnic identity politics as a dialectical struggle for power by dominant and subordinate groups through the means of ethnic identity to maneuver their education system such as by adopting inclusive curriculum. 